\title{
28 Research Suare \\ Experience of Using An e-portfolio In Clinical Practice at a Medical School
}

\section{Mi Ryoung Song}

Ajou University School of Medicine

Ji Hye Yu

Ajou University School of Medicine

Mi Jin Lee

Ajou University School of Medicine

Su Kyung Lee

Ajou University School of Medicine

Mi Ran Kim

Ajou University School of Medicine

So Young Moon

Ajou University School of Medicine

Jang Hoon Lee ( $\nabla$ neopedlee@aumc.ac.kr)

Ajou University School of Medicine

\section{Research Article}

Keywords: E-Portfolio, Feedback, Portfolio, Medical students, Clinical practice

Posted Date: September 30th, 2021

DOI: https://doi.org/10.21203/rs.3.rs-900124/v1

License: (c) (i) This work is licensed under a Creative Commons Attribution 4.0 International License.

Read Full License 


\section{Abstract}

Background: The electronic portfolio(e-portfolio) is a useful tool for storing learning-related information, gathering and organizing learning evidence, and demonstrating student learning and growth over time. According to various studies, e-portfolio content criteria should be kept simple and adaptable in relation to educational aims. However, there is a paucity of empirical studies on whether the content composition of an e-portfolio as seen by learners using the real e-portfolio is acceptable. The purpose of this study is to determine whether the appropriateness of electronic portfolio content items and feedback affects selfreflection and learning ability in clinical practice for medical students who used an electronic portfolio.

Methods: This research was carried out in 2020 with 40 fifth-grade students at Ajou University College of Medicine in Korea. The benefits and utility of e-portfolios were investigated in clinical practice courses in pediatrics, obstetrics and gynecology, and neurology. Descriptive statistics, analysis of variance (ANOVA), correlation analysis, and a regression analysis were performed on the obtained data.

Results: Satisfaction with neurology was the greatest among the clinical practice courses in pediatrics, obstetrics and gynecology, and neurology as compared to clinical practice course using an e-portfolio for the first time. Self-reflection, learning performance improvement, and prompt feedback were all found to be more satisfying than in previous clinical practice courses. Furthermore, as the quantity of content items in the e-portfolio dropped and the faculty in charge rapidly provided feedback, medical students' satisfaction with e-portfolio usage increased.

Conclusions: The number of content items in the e-portfolio decreased as the number of content items in the e-portfolio declined in the clinical practice course of the medical school; moreover, the faculty in charge provided timely feedback. This suggests that for medical students to effectively use the eportfolio in the clinical practice course, a plan should be developed to reduce the number of e-portfolio content items. Subsequently, there should be a focus on the most important items while considering the unique characteristics of each clinical practice course. It also indicates that professors should provide prompt feedback on students' academic performances.

\section{Background}

A portfolio is a learning tool that allows students to track their progress and develop competency improvement plans based on feedback received during the learning process and while completing assignments. When the paper-based portfolio was first introduced in the mid-1980s [1], it drew the attention of educators [2]. As digital innovation technology advanced, the paper-based portfolio was then replaced by an e-portfolio to address accessibility and management issues [3]. In general, a web-based eportfolio is a useful tool for storing learning-related information, gathering and organizing learning evidence, and demonstrating student learning and growth over time [3, 4]. An e-portfolio is more userfriendly than a paper-based portfolio and has several advantages, including a lower risk of data loss; easier access and management [5]; and the ability to receive feedback from faculty from anywhere with 
an internet connection $[6,7,8,9,10,11]$. Feedback may be sent between students and teachers regardless of place or time, and can foster experiential learning, critical self-reflection, and self-regulation if the eportfolio is utilized in the medical education area [12]. Faculty can also use an e-portfolio to track students' development and provide timely and constructive comments $[12,13]$. Consequently, the eportfolio may be a useful instrument for promoting critical reflection in the writing process, assisting learners in self-directed learning, and facilitating contact and feedback between students and instructors.

The e-portfolio relies heavily on feedback. To enhance learners' performance and competency, feedback should be delivered in specific and constructive content that is aligned with the learning goals [8]. In competency-based medical education, evaluation and feedback are often used to assess the potential and competencies of students $[4,14]$. Positive research findings show that e-portfolio feedback motivates users to reflect, and that feedback may be used to reflect on and plan future learning activities. In contrast, there have been reports of skepticism regarding the e-portfolio tool, the time commitment required for writing, and the fact that the e-portfolio has not resulted in deep learning $[14,15,16,17]$. Even though the results of these studies differ, it is widely assumed that feedback is a significant aspect in the use of e-portfolios in medical education. In reality, it is vital to investigate the elements that influence the impact of e-portfolio feedback on the opinions of learners who have used the tool.

Notably, when educational goals are not clearly defined between students and teachers, the e-portfolio is frequently utilized to incorporate a large amount of content in the content composition [18]. Because of the imprecise requirements on the ways to construct an e-portfolio, students may form a negative opinion that they have extensively written an e-portfolio, and they may spend more time writing an e-portfolio than necessary. Therefore, according to various studies, e-portfolio content criteria should be kept simple and adaptable in relation to educational aims $[18,19]$. However, there is a paucity of empirical studies on whether the content composition of an e-portfolio as seen by learners using the real e-portfolio is acceptable.

The purpose of this study is to determine whether the appropriateness of electronic portfolio content items and feedback affects self-reflection and learning ability in clinical practice for fifth-grade medical students who used an electronic portfolio in their first year of medical school at Ajou University. Accordingly, the research questions were based on the study's purpose.

First, is there a variation in student satisfaction for each clinical practice course based on the content composition?

Second, how does e-portfolio feedback influence students' learning outcomes and self-performance?

\section{Methods}

\section{The design of the e-portfolio}


The Korea Association of Medical Colleges (KAMC) e-portfolio consortium's ubiquitous portfolio (UFOLION) in the Healthcare educational technology (EDUTECH) e-portfolio system was used in this study.

The e-portfolio was first used in clinical practice at the Ajou University School of Medicine in 2020. Internal medicine, surgery, obstetrics and gynecology, pediatrics, psychiatry, neurology, and family medicine are among the seven clinical practice courses available to fifth-grade medical students. Eportfolio was used in pediatrics, obstetrics and gynecology, and neurology.

Furthermore, each faculty member chose the e-content portfolio to match the educational aims and features of each clinical practice course. Table 1 shows the topics chosen after examining the peculiarities of each clinical practice course.

Table 1

Content composition items of e-portfolio by clinical practice course of medical school

\begin{tabular}{|c|c|c|c|c|}
\hline Questions & & Pediatrics & $\begin{array}{l}\text { Obstetrics \& } \\
\text { Gynecology }\end{array}$ & Neurology \\
\hline \multirow{7}{*}{$\begin{array}{l}\text { Planning and } \\
\text { Reflection }\end{array}$} & Daily practice record. & 0 & 0 & 0 \\
\hline & Weekly practice plan and reflection & 0 & 0 & 0 \\
\hline & Final reflection & 0 & 0 & 0 \\
\hline & $\begin{array}{l}\text { Clinical presentation planning and } \\
\text { self-evaluation }\end{array}$ & 0 & 0 & 0 \\
\hline & $\begin{array}{l}\text { Clinical skills planning and self- } \\
\text { evaluation }\end{array}$ & 0 & 0 & 0 \\
\hline & $\begin{array}{l}\text { Attitude assessment (Professor } \\
360 \text { Assessment) }\end{array}$ & 0 & 0 & 0 \\
\hline & Docility & 0 & 0 & - \\
\hline \multirow{3}{*}{$\begin{array}{l}\text { Clinical } \\
\text { Presentation }\end{array}$} & Outpatient preliminary record & 0 & 0 & 0 \\
\hline & $\begin{array}{l}\text { Inpatient medical records of } \\
\text { inpatients }\end{array}$ & 0 & 0 & - \\
\hline & Inpatient case presentation & 0 & 0 & 0 \\
\hline \multirow[t]{3}{*}{ Clinical Skills } & Clinical skills (rubric evaluation) & 0 & 0 & 0 \\
\hline & Clinical skills (observation) & 0 & 0 & - \\
\hline & Surgical observation record & 0 & - & - \\
\hline \multirow[t]{3}{*}{ Others } & Topic presentation & 0 & - & - \\
\hline & Journal review & 0 & 0 & - \\
\hline & English presentation & 0 & - & - \\
\hline
\end{tabular}


An online survey was administered in December 2020 at the completion of clinical practice for 40 fifthgrade students who participated in the clinical practice course at Ajou University School of Medicine in Gyeonggi-do, Republic of Korea, from June to December 2020. All 40 participants answered the survey.

\section{Questionnaire}

Data were acquired by generating questionnaire items on the benefits and satisfaction of utilizing an eportfolio in the clinical practice course of pediatrics, obstetrics and gynecology, and neurology. We studied the literature review linked to the use of an e-portfolio in clinical practice and composed a total of six questions about the benefits and effectiveness of using an e-portfolio in clinical practice during the clinical practice course. On a five-point Likert scale, four questions on enhancing clinical practice, introspection, self-directed learning skills, appropriateness of the amount of content composition items, and prompt feedback were studied using an e-portfolio.

\section{Analysis}

Descriptive statistics, analysis of variance (ANOVA), correlation analysis, and a regression analysis were performed on the obtained data; additionally, jamovi version 1.8.2 was used to analyze the data. The average and standard deviation of each question were calculated to determine whether students in clinical practice were satisfied with their e-portfolio usage, and the ANOVA and Scheffës post hoc test were used to determine whether there was a difference in e-portfolio usage satisfaction by clinical practice course. The appropriateness of the number of content items while using the e-portfolio, as well as whether faculty input influences students' learning ability and self-reflection, were investigated using correlation and regression analysis.

\section{Results}

Table 2 illustrates the results of each clinical practice course's e-portfolio usage experience and perception of learning gains.

Neurologists valued the experience and benefits of e-portfolios more than pediatricians, obstetricians, and gynecologists in clinical practice. In particular, the e-portfolio is useful for reflecting on clinical practice experience $(F=3.37, p<.05)$ and the feedback received from the e-portfolio helps to improve learning and performance $(F=4.94, p<.001)$. There were statistically significant differences in whether the amount of content was adequate $(F=3.11, p<.05)$ and whether the faculty in charge gave quick feedback $(F=9.75$, $\mathrm{p}<.001)$ on the submitted assignments. 
Table 2

Experience of using e-portfolio by clinical practice course and awareness of benefits

Questions

Mean(SD)

$\mathbf{F}$

Pediatrics Obstetrics Neurology

Gynecology

1 The e-portfolio was helpful in comprehending the practice goals and the

overall training process.

$2.20(1.04) \quad 2.73(1.13) \quad 2.58$

2 The e-portfolio has been helpful in reflecting on my clinical practice experience.

$2.45(1.01)$

$2.27(1.11)$

$2.88(1.07)$

$3.37^{*}$

2.38(0.98)

$2.20(1.04)$

2.58

3 My ability to learn on my own is enhanced by the e-portfolio.

$2.20(1.04) \quad 2.27(1.15) \quad 2.60(1.11)$

1.51

4 The e-portfolio comments I received aided me in improving my learning and

2.60(0.93)

2.27(1.11)

$3.05(1.26)$

$4.94^{\star *}$ performance.

5 The number of content items in the eportfolio was adequate.

$2.20(0.97) \quad 2.05(1.15) \quad 2.63(1.08)$

$3.11^{*}$

6 The e-portfolio submission assignment was swiftly evaluated by the faculty in charge.

2.73(1.09)

2.30(1.20)

$3.45(1.24)$

$9.75^{\star \star \star}$

${ }^{*} p<0.05,{ }^{* *} p<0.01,{ }^{* * *} p<0.001$

Table 3 shows the relationship between the amount of e-portfolio content items, fast feedback, and the advantages of using an e-portfolio for learning (reflection, self-directed learning, learning, performance ability, etc.). Students' self-reflection, self-directed learning capacity, and learning and performance ability were all positively correlated with the amount of content items in the e-portfolio and the rapid supply of feedback by the faculty in charge.

Table 3

The relationship between e-portfolio content items, feedback, and e-portfolio usage experience Questions Content

Feedback items

The e-portfolio was helpful in comprehending the practice goals and the overall training process.

$0.658^{\star \star \star} \quad 0.531^{\star \star \star}$

The e-portfolio has been helpful in reflecting on my clinical practice experience.

$0.679^{\star \star \star} \quad 0.573^{\star \star \star}$

My ability to learn on my own is enhanced by the e-portfolio.

$0.681^{* \star *}$

$0.419^{\star \star \star}$

The e-portfolio comments I received aided me in improving my learning and performance.

$0.618^{\star \star \star}$

$0.702^{\star \star \star}$

${ }^{\star \star \star} p<0.001$ 
Table 4 shows the outcomes of managing the characteristics of each clinical practice section for the benefits of learning using an e-portfolio; also, confirms the appropriateness of the number of content items and the impact of the faculty's prompt feedback. The amount of e-portfolio content items and the regression equation of e-portfolio learning advantages for rapid faculty feedback were both statistically significant in the clinical practice process $(F=71.50, p<.001)$. Predictive variables connected to $\mathrm{e}-$ portfolio content items and feedback had a predictive power of approximately $56 \%$ when it came to the learning benefit of the e-portfolio (Adj $R^{2}=0.56$ ). In terms of the benefits of e-learning portfolios, it was discovered that the amount of content items in the e-portfolio was viewed as appropriate $(\beta=0.55, p$ $<.001)$ and the awareness that the faculty offered quick feedback $(\beta=0.29, p<.001)$ had a statistically significant effect. In other words, the more appropriate the quantity of e-portfolio content items employed in clinical practice, the faster faculty evaluation is supplied, then the e-learning portfolio's advantages of introspection, self-directed learning, and learning performance are more positively impacted.

Table 4

The regression coefficient of predictor variables for the benefits of using an e-portfolio

\begin{tabular}{|c|c|c|c|c|c|c|c|c|}
\hline Variable & Mode & & & & Model 2 & & & \\
\hline Unstandardiz & & Standardized & $\mathrm{t}$ & Unsta & Jardized & Standardized & $\mathrm{t}$ & \\
\hline & & Coefficients & & & & Coefficients & & \\
\hline B & $\begin{array}{l}\text { Std. } \\
\text { Error }\end{array}$ & $\beta$ & & B & $\begin{array}{l}\text { Std. } \\
\text { Error }\end{array}$ & $\beta$ & & \\
\hline $\begin{array}{l}\text { Clinical } \\
\text { practice } \\
\text { course }\end{array}$ & 0.56 & 0.22 & 0.56 & $2.53^{*}$ & -0.005 & 0.16 & -0.005 & -0.03 \\
\hline $2-1$ & & & & & & & & \\
\hline $3-1$ & 0.15 & 0.22 & 0.15 & 0.68 & -0.025 & 0.15 & -0.025 & -0.17 \\
\hline $\begin{array}{l}\text { Content } \\
\text { items }\end{array}$ & & & & & 0.51 & 0.07 & 0.55 & $7.47^{\star \star \star}$ \\
\hline Feedback & & & & & 0.23 & 0.06 & 0.29 & $3.75^{\star \star \star}$ \\
\hline & $R^{2}=0$ & $6, \operatorname{adj} . R^{2}=0.04$ & $=3.43$ & & $\mathrm{R}^{2}=0.5$ & $\operatorname{dj} . R^{2}=0.56, F$ & $39.53^{\star \star \star}$ & \\
\hline$\Delta R^{2}=0.524$, & $=71.5$ & & & & & & & \\
\hline 1: Obstetrics & Gynec & ogy, 2: Neurolo & y, 3: Pe & iatrics & & & & \\
\hline${ }^{*} p<0.05,{ }^{* \star \star}$ & 001 & & & & & & & \\
\hline
\end{tabular}

\section{Discussion}


The goal of this research was to develop a specific application plan for using an e-portfolio to encourage learning in the fifth grade of clinical practice courses and to improve learning management efficiency. For this purpose, we examined the utility of using an e-portfolio in clinical practice courses as well as how satisfaction with the use of an e-portfolio in clinical practice courses is influenced by the appropriateness of content composition and feedback.

With regard to our research findings, first we discovered students' perceptions of e-portfolio learning gains and satisfaction varied depending on the e-portfolio material composition for each clinical practice course. During clinical practice courses, there were differences in the composition of e-portfolio items for pediatrics, obstetrics and gynecology, and neurology. Daily practice records, weekly practice records, attitude assessment, outpatient prognostic records, inpatient medical records, clinical skills rubric assessment, and inpatient proportion presentation were some of the most common e-portfolio content items used in pediatric, gynecological, and neurology clinical practice processes. Clinical skills observation and journal presentation were also used as e-portfolio content components in gynecology and pediatric clinical practice. Throughout the course of obstetrics and gynecology clinical practice, elements such as surgical observation records were employed as e-portfolio content items. These eportfolio content items are primarily for students to keep track of on a continual basis and it can be seen that the greater the amount of content items, the more time students must dedicate to establishing an eportfolio. So, because the aim of an e-portfolio in the clinical practice process is unclear at first, many attempts have been made to include a large amount of content in e-portfolio content [18]. According to Driessen [18], tailoring portfolios to the needs of professors and students can be beneficial. The competences and learning goals to be reached should be clearly given, and the contents of the e-portfolio should be correctly organized in order to use the e-portfolio in the clinical practice course to enjoy the benefits and consequences of learning.

Furthermore, the more they identified that the e-portfolio's content structure was suitable, the more favorable their responses to the learning advantages were. Specifically, when utilizing the e-portfolio, this is related to the content composition. The e-portfolio's contents should be organized in line with the clinical practice course's educational aims with no superfluous or overlapping elements. According to Vance et al. [19], information created in an e-portfolio without a clear purpose hinders student engagement, and content development and writing should be concise and flexible to promote student participation. According to the findings of this study, the number of e-portfolio items was determined to be a factor determining the learning benefit. Therefore, it is critical to clearly identify the learning goals and skills for each clinical practice course, as well as to arrange the e-portfolio contents simply according to the aim, in order to improve e-portfolio utilization.

Next, faculty evaluation was rapidly delivered in the clinical practice course, which increased the benefits of e-learning portfolios (reflection, self-directed learning, learning, and performance ability). In the following paragraph, we present a list of the providers of feedback from pediatric adolescents, obstetrics and gynecology, and neurology who participated in this study. 
While other clinical practice courses provided little or no feedback, the neurology clinical practice course's responsible professor provided immediate feedback on each student's learning record, such as daily feedback on daily records. Students' perceptions of the e-portfolio's learning benefits appear to have been influenced by this difference in feedback. Providing students with regular and timely feedback, in other words, may help them stay motivated and achieve excellent learning results. According to Bleasel et al. [17], providing exact feedback at the correct time is more important than the volume of feedback supplied. Watling [20] also noted that excellent feedback can only be provided at an appropriate time. As a result, it was verified that providing fast feedback to students in the e-portfolio is an essential aspect for clinical faculty.

First, with regard to the study's importance and implications, this research looked at student satisfaction with the use of e-portfolios in the first year after they were introduced. In a scenario where there is little research on the use of e-portfolios, it is worthwhile to examine the satisfaction of utilizing e-portfolio content by considering the features of each course in the clinical practice process for medical students. Accordingly, because it was the first year of using an e-portfolio, there was no instruction on how to organize and use the content. A satisfaction survey was conducted with students who used the eportfolio for the first time, and attempts were made to discover variables for content creation and satisfaction enhancement in order to successfully use the e-portfolio that is used as an advantage for students' learning in the future. Hence, satisfaction with utilizing an e-portfolio was highest in the neurology clinical practice course in this study, which included pediatric, obstetrics, gynecology, and neurology clinical practice courses. When compared to other clinical practice courses, the e-portfolio content items in neurology clinical practice courses were minimized. When it comes to using the eportfolio, students want to be succinct and obtain what they want. It was verified once again that the appropriateness of information creation is a key component in building a student-friendly e-portfolio and increasing user satisfaction. According to previous research, the number of content items in the eportfolio should be succinct and adaptable according to the learning goal to promote participation in the e-portfolio and enhance the efficacy of learning $[18,19]$. In fact, Vance et al. [19] questioned clinical practice students in the United Kingdom about their use of e-portfolios, concluding that content configurations that reduce the time, repetition, and duplication of the process should be accomplished to encourage e-portfolio participation. As a result, the degree of content composition elements should be adjusted according to the learning objective to maximize the learning effect of using the e-portfolio.

Second, this study discovered that feedback is a key element in increasing an e-portfolio's learning advantage. In competency-based medical education, feedback for learners is a significant topic of study. This study indicates that if the faculty offers timely observations on the feedback utilizing the e-portfolio, it aids learners in self-reflection and academic achievement. Research on the efficacy of learning from feedback recognized by students and teachers at a medical education site discovered that feedback becomes more timely, detailed, and constructive $[17,20]$. Consequently, a system for delivering detailed feedback must be prepared to maximize the learning advantages of utilizing the e-portfolio. 
Notably, there were some shortcomings in this study. The questionnaires were created based on a review of prior studies on the use of e-portfolios; moreover, the satisfaction with the usage of e-portfolios was evaluated. An e-portfolio user satisfaction survey tool is required to perform an e-portfolio user satisfaction survey on a continual basis. The number of questions on assessment and feedback in this study were from one to two of them concerning the confirmation of the link between evaluation and feedback when using an e-portfolio. So, there is a limit that does not include complete e-portfolio evaluation and feedback, such as the suitability of the content development range and questions about particular feedback techniques. Therefore, we recommend that future studies on learning advantages, such as complete feedback on evaluation items and content design, feedback timing, provider, quality, etc. while utilizing an e-portfolio, will need to be more empirically performed.

\section{Conclusions}

This research discovered that student satisfaction with the use of an e-portfolio varies depending on the composition and functioning of e-portfolio content items in a clinical practice course. The number of content items in the e-portfolio decreased as the number of content items in the e-portfolio declined in the clinical practice course of the medical school; moreover, the faculty in charge provided timely feedback. This suggests that for medical students to effectively use the e-portfolio in the clinical practice course, a plan should be developed to reduce the number of e-portfolio content items. Subsequently, there should be a focus on the most important items while considering the unique characteristics of each clinical practice course. It also indicates that professors should provide prompt feedback on students' academic performances.

\section{Abbreviations}

ANOVA: analysis of variance

e-portfolio: electronic portfolio

KAMC : Korea Association of Medical Colleges

U-FOLION: ubiquitous portfolio

EDUTECH : Educational technology

\section{Declarations}

\section{Ethics Approval and Consent to Participate}

This study was approved by the Institutional Review Board (IRB) of Ajou University Hospital (Ethics consent No. AJIRB-SBR-SUR-21-078). All methods were carried out in accordance with relevant guidelines and regulations. Informed consent was implied by completion and submission of the anonymous survey. 


\section{Consent for Publication}

Not applicable.

\section{Availability of Data and Materials}

The datasets used this article are available from the corresponding author on reasonable request.

\section{Competing Interests}

The authors declare that they have no competing interests.

\section{Funding}

No funding was obtained for this study.

\section{Authors' Contributions}

MRS, JHL, JHY, SKL, MRK and SYM participated in designing the study. JHY, JHL, SKL and MJL developed the questionnaire. MRS was involved in the literature review, data analysis, and manuscript drafting. JHY and JHL contributed to the collection and analysis of data, and critical revision of the manuscript for important intellectual content. SKL and MJL contributed to the collection of data and critical revision of the manuscript for important intellectual content. All authors read and approved the final manuscript.

\section{Acknowledgments}

All authors appreciate to the students who participated in this study. All authors would like to thank Editage (www.editage.co.kr) for English language editing.

\section{Authors' information}

\section{Affiliations}

Office of Medical Education, Ajou University School of Medicine, Suwon, South Korea Ji Hye Yu \& Mi Ryoung Song

Department of Medical Humanities \& Social Medicine, Ajou University School of Medicine, Suwon, South Korea

Mi Jin Lee

Ajou Center for Clinical Excellence, Ajou University School of Medicine, Suwon, South Korea Su Kyung Lee 
Department of Obstetrics \& Gynecology, Ajou University School of Medicine, Suwon, South Korea

Mi Ran Kim

Department of Neurology, Ajou University School of Medicine, Suwon, South Korea

So Young Moon

Department of Pediatrics, Ajou University School of Medicine, Suwon, South Korea

Jang Hoon Lee

\section{References}

1. Lorenzo G, Ittelson J. An overview of E-portfolios, Educause Learning Initiative advancing learning through IT innovation. 2005;1-27.

2. Gerbic P, Lewis L, Northover M. Student perspectives of eportfolios: a longitudinal study of growth and development. Ascilite Conference, Auckland, New Zealand. 2009;327-331.

3. Lewis KO, Baker RC. The development of an electronic educational portfolio: an outline for medical education professionals. Teach Learn Med. 2007; doi:10.1080/10401330701332219.

4. Buckley S, Coleman J, Davison I, Khan KS, Zamora J, Malick S, Morley D, Pollard D, Ashcroft T, Popovic C, Sayers J. The educational effects of portfolios on undergraduate student learning: a Best Evidence Medical Education (BEME) systematic review. BEME Guide No. 11. Med Teach. 2009; doi:10.1080/01421590902889897.

5. Ambrose GA, Chen HL. 360 Folio networking: enhancing advising interactions and expanding mentoring opportunities with ePortfolios. Theory Into Pract. 2015;54:317-325.

6. Peeraer G, Van Humbeeck B, De Leyn P, Delvaux G, Hubens G, Pattyn P, De Win G. The development of an electronic portfolio for postgraduate surgical training in Flanders. Acta Chirurgica Belgica. 2015; doi:10.1080/00015458.2015.11681069.

7. Driessen EW, Muijtjens AM, van Tartwijk J, et al. Web- or paper-based portfolios: is there a difference? Med Educ. 2007; doi:10.1111/j.1365-2923.2007.02859.x.

8. Van Tartwijk J, Driessen EW. Portfolios for assessment and learning: AMEE guide no. 45. Med Teach. 2009;31:790-801.

9. Hawks SJ. The use of electronic portfolios in nurse anesthesia education and practice. AANA J. 2012;80:89-93.

10. Green J, Wyllie A, Jackson D. Electronic portfolios in nursing education: a review of the literature. Nurse Educ Pract. 2014;14:4-8.

11. De Swardt, M, Jenkins, LS, Von Pressentin, KB, Mash R. Implementing and evaluating an e-portfolio for postgraduate family medicine training in the Western Cape, South Africa. BMC Med Educ. 2019; doi:10.1186/s12909-019-1692-x. 
12. van der Schaaf M, Donkers J, Slof B, Moonen-van Loon J, van Tartwijk J, Driessen E. Improving workplace-based assessment and feedback by an e-portfolio enhanced with learning analytics. Educ Technol Res Dev. 2017;65:359-380.

13. Yang M, Tai M, Lim CP. The role of e-portfolios in supporting productive learning. Br J Educ Technol. 2016;47:1276-1286.

14. Fu, RH, Cho YH, Quattri F, Monrouxe LV. 'I did not check if the teacher gave feedback': a qualitative analysis of Taiwanese postgraduate year 1 trainees' talk around e-portfolio feedback-seeking behaviours. BMJ Open. 2019; doi:10.1136/bmjopen-2018-024425.

15. Tochel C, Haig A, Hesketh A, Cadzow A, Beggs K, Colthart I, Peacock H. The effectiveness of portfolios for post-graduate assessment and education: BEME Guide No 12. Med Teach. 2009; doi:10.1080/01421590902883056.

16. Mok J. As a student, I do think that the learning effectiveness of electronic portfolios depends, to quite a large extent, on the attitude of students! ELT Journal of e-learning. 2012;10:407-416.

17. Bleasel J, Burgess A, Weeks R, Haq I. Feedback using an ePortfolio for medicine long cases: quality not quantity. BMC Med Educ. 2016; doi:10.1186/s12909-016-0801-3.

18. Driessen E. Portfolio critics: Do they have a point? Med Teach. 2009; doi:10.1080/01421590902803104.

19. Vance, GHS, Burford B, Shapiro E, Price R. Longitudinal evaluation of a pilot e-portfolio-based supervision programme for final year medical students: views of students, supervisors and new graduates. BMC Med Educ. 2017; doi:10.1186/s12909-017-0981-5.

20. Watling CJ. Unfulfilled promise, untapped potential: feedback at the crossroads. Med Teach. 2014;36: 692-7. 